\title{
CONSTRUÇÃO DE NOVOS OLHARES A PARTIR DO CINEMA: ENCENANDO NOVAS EDUCAÇÕES, SEXUALIDADES E DES-GÊNEROS
}

\author{
CARLOS AUGUSTO SILVA ${ }^{1}$ \\ DHEMERSSON WARLY SANTOS COSTA ${ }^{2}$
}

\begin{abstract}
Resumo: Este ensaio objetiva pensar a sexualidade a partir do cinema, em especial, os filmes Elvis $e$ Madona e Uma Nova Amiga, subvertendo a ideia de gênero e identidade estabelecidas socialmente: homem/mulher, gay/lésbica... Refletindo, ainda, sobre as produções imagéticas de pensamentos e práticas ativadoras de modos de afetação das imagens, dos filmes supracitados suscitando novas possibilidades de pensar o ser humano, corpo e cinema. Convidando-(n/os) a perguntar: o que pode o cinema como artefato para pensar a sexualidade na educação e no deslocamento dos gêneros? Para tanto, serão trazidos e problematizados, além dos filmes, pequenas frases e fragmentos de textos produzidos por três professorxs de Ciências Biológicas e umx alunx do ensino médio, que tiveram o encontro com essas obras cinematográficas e fizeram uma relação com a sexualidade e a escola. Traremos os teóricos Gilles Deleuze e Félix Guattari, bem como Alain Bergala e Jean-Luc-Godard como uma caixa de ferramentas para possibilitar novas maneiras de ver e pensar a sexualidade com o cinema. Serão intercessores para uma configuração do pensamento por desterritorializações, deslocamentos.

Palavras-chave: Educação. Cinema. Des-gênero.
\end{abstract}

Resumen: Este ensayo tiene como objetivo pensar la sexualidad a partir del cine: en especial, de las películas Elvis e Madona y Une nouvelle amie, subvirtiendo la idea de género e identidad establecidas socialmente: hombre/mujer, gay/lesbiana... También reflexiona sobre las producciones imagéticas de pensamientos y las prácticas activadoras de los modos de afectación de las imágenes, de las películas citadas, suscitando nuevas posibilidades de pensar el ser humano, cuerpo y cine. Convidándonos a preguntar: ¿qué poder tiene el cine como artefacto para pensar la sexualidad en la educación y en el pesplazamiento de los géneros? Para ello, serán presentados y problematizados, además de las películas, pequeñas frases y fragmentos de textos producidos por tres profesorxs de Ciencias Biológicas y unx alumnx de enseñanza media, que tuvieron el encuentro con esas obras cinematográficas e hicieron una relación con la sexualidad y la escuela. Citaremos a los teóricos Gilles Deleuze e Féliz Guattari, así como Alain Bergala e Jean-Luc Godard como una caja de herramientas para posibilitar nuevas formas de ver y pensar la sexualidad con el cine. Serán intermediarios para una configuración del pensamiento por desterritorializaciones, desplazamientos.

Palabras clave: educación, cine, des-género.

\footnotetext{
${ }^{1}$ Possui graduação em Ciências Biológicas pela Universidade Federal do Pará (2014), tendo experiência na área da educação com ênfase no ensino/aprendizagem em ciências e formação de professores. Atualmente é aluno de Mestrado pelo Programa de Pós-Graduação em Educação em Ciências e Matemáticas, Universidade Federal do Pará e especialização em andamento em metodologia do ensino de biologia e química.

2 Possui graduação em licenciatura em Ciências Biológicas pela Universidade Federal do Pará (2016) campus de Altamira-PA. Atuou como bolsista no programa de iniciação a docência PIBID (2012-2014). Foi bolsista do projeto de extensão EDUCABIO (2014-2015). Têm experiência na área de ensino e aprendizagem de Ciências, Currículo de Ciências Biológicas e Formação inicial de professores de Ciências Biológicas. Atualmente é mestrando do Programa de Pós-Graduação em Ciências e Matemáticas pela UFPA
}

Rev. Diversidade e Educação, v. 5, n. 1, p. 42-50, jan./jun. 2017. 


\begin{abstract}
This essay aims at thinking the sexuality from cinema, in particular the films Elvis \& Madona and Une nouvelle amie, subverting the idea of gender and identity socially established: man/woman, gay/lesbian. Reflecting, still, about imagery productions of thoughts and practices that activate ways of image affectation from the films mentioned above, raising new possibilities of thinking about the human being, body and cinema. Inviting us to ask: what can the cinema as artifact to think the sexuality in education and gender dislocation? Therefore, it will be brought and questioned, besides the films, little sentences and text fragments produced by three teachers of Biological Sciences and a student from high school that encountered those cinematographic works and were able to create a connection with sexuality and school. We will bring theoreticals Gilles Deleuze and Félix Guattari, as well as Alain Bergala and Jean-Luc-Godard as a toolbox to enable new ways of seeing and thinking the sexuality with the cinema. They will be intercessors to a configuration of thinking for deterritorializations, dislocations.
\end{abstract}

Keywords: education, cinema, de-gender

\title{
Margens Introdutórias
}

A presente pesquisa almeja pensar a sexualidade a partir do cinema, em especial, os filmes Elvis e Madona (2011) e Uma Nova Amiga (2014) ${ }^{4}$. Reflete, ainda, sobre as produções imagéticas de pensamentos e práticas ativadoras de modos de afetação das imagens, dos filmes supracitados. Convida-(n/os) a pensar: o que pode o cinema como artefato para pensar a sexualidade na educação?

Trata-se do recorte de uma pesquisa que visa trazer questões sobre cinema, literatura $e$ sexualidade. Os integrantes do estudo fazem parte de uma escola pública, sob o qual anteriormente(foi realizado um levantamento de ações sobre sexualidade. Para tanto, serão trazidos e problematizados, além dos filmes, pequenas frases e fragmentos de textos produzidos por três professorxs de Ciências Biológicas e umx alunx do ensino médio, que tiveram o encontro com essas obras cinematográficas e fizeram uma relação com a sexualidade e a escola.

Além dos filmes, os quais consideramos artefatos valiosos para pensar a sexualidade, traremos os teóricos Gilles Deleuze e Félix Guattari, bem como os comentaristas franceses do cinema Alain Bergala e Jean-Luc-Godard como uma caixa de ferramentas para possibilitar novas maneiras de ver e pensar a sexualidade com o cinema.

\footnotetext{
3 "Elvis e Madona" é um filme brasileiro dirigido pelo cineasta Marcelo Laffitte que conta a confusa história de um casal formado por uma lésbica e uma travesti. Elvis (Elvira) sonha em ser fotógrafa, mas a necessidade de sustento faz com que aceite o emprego de entregadora de pizza. Madona é uma travesti que trabalha como cabeleireira, mas que sonha em produzir uma peça de teatro. As personagens da história tornam-se grandes amigas. Todavia, pouco a pouco, o sentimento de amizade dar lugar a uma bonita e improvável história de amor.

4 "Uma Nova Amiga" é um filme Frances dirigido por François Ozon. Na trama, a melhor amiga de Claire, uma das personagens centrais da narrativa, fica doente e morre. Com a perda da amiga, Claire resolve buscar no marido dela apoio para continuar prosseguindo, todavia mal sabia ela que esse seria o inicio de uma surpreendente amizade com uma nova amiga.
}

Rev. Diversidade e Educação, v. 5, n. 1, p. 42-50, jan./jun. 2017. 


\section{Cinema e Sexualidade: algumas considerações}

A arte não se ensina, experiencia! Alain Bergala

Começo este fragmento do texto pensando com Alain Bergala, cineasta e escritor francês que foi fortemente influenciado por Jean-Luc Godard. Poderia de fato o cinema entrar nas diretrizes curriculares dos cursos de Ciências Biológicas ou na escola básica, subsidiando na formação de alunxs e professorxs? É no sentido de tentar buscar possíveis respostas para esta afirmação que compartilho do pensamento de Bergala (2008, p. 29) quando este afirma que:

Toda forma de enclausuramento nessa lógica disciplinar reduziria o alcance simbólico da arte e sua potência de revelação, no sentido fotográfico do termo. A arte, para permanecer arte, deve permanecer um fermento de anarquia, de escândalo, de desordem.

Não pretendo realizar, no momento, uma discussão sobre se seria correto à arte-cinema entrar nos currículos de maneira disciplinar, o que mais me interessa no momento é pensar esta arte como bem nos diz Bergala na citação anterior que "deve permanecer um fermento de anarquia, de escândalo, de desordem". Não me importando muito se esta desordem no pensamento dos alunxs se dará de maneira disciplinar ou não, penso que estas palavras possam ter pesado aos olhos do leitxr, mas, percebo tal desordem escandalosa como possibilidades que podem ser acionadas a partir do cinema no pensamento, e, possivelmente em práticas.

O cinema, como produção artística, é uma forma do pensamento (DELEUZE, 2007). Sendo assim, xs cineastas são pensadorxs que, através da sétima arte possuem a possibilidade de produzir um cinema que cambiam pela política, potencializando a resistência que é apresentada no cinema e vai para além deste. Portanto, o cinema pode se tornar um elemento perturbador de uma instituição (BERGALA, 2008) de ensino, seja ela superior ou de educação básica.

Perturbador no sentido de borrar os sistemas moralísticos e rígidos, comportamentais e estruturais. Destarte acrescentar que, o cinema não deve ser pensado como uma chave que irá erradicar todos os problemas de formação de alunxs e professorxs, mas, sobretudo, torna- se um caminho para se pensar outros modos de conduzir as trilhas vitais no mundo, quem sabe inclusive criar outras. Penso essas trilhas como caminhos que são fabulados para fazer o indivíduo respirar, pois, é num mar de sistemas que indicam a melhor ou única forma de estar no mundo.

O cinema pode ser experimentado por outras vias, não apenas pelas comumente impostas Rev. Diversidade e Educação, v. 5, n. 1, p. 42-50, jan./jun. 2017. 
pelos sistemas oficiais de educação. Buscando através da arte, resistir e criar para si novas possibilidades, pois é da natureza das instituições neutralizarem ou coibir tais manifestações que tentam fissurar uma moral.

O cinema nos faz perceber os mundos, as multiplicidades que nos cercam, ou estão presentes, inclusive, em nós mesmxs, tudo isso, também, através de compartilhamento de experiências, eventos e histórias, nos fazendo sentir-se nx outrx, ou em nós mesmos, exercendo assim, a alteridade.

Tendo em vista o exposto até o momento, penso sobre qual o potencial do cinema quando este traz temas relacionados à sexualidade na escola.

Dentro das instituições formais de ensino como a escola, os discursos sobre sexualidade e gênero embasam-se sobre os pilares científicos, ou seja, biológicos (homem ou mulher). Tais lentes de conhecimentos produzem discursos através dos seus preceitos racionalizantes, que buscam sistematizar a sexualidade ajustando condutas aos corpos, condensando, também, a sexualidade numa perspectiva meramente biologizante-medicinista-higienista, a qual enxerta as grades curriculares, predominando explicações anatômicas e fisiológicas para tais atravessamentos inerentes a sexualidade, presentes, também, nas falas de discentes e docentes, produzindo além de uma verdade, uma única forma de ver, estar, ser, e pensar o mundo, bem como as forças que os cercam (SANTOS; BRITO, 2014).

No entanto, existem conhecimentos sendo produzidos e tencionados, principalmente fora destes muros curriculares de verdades. Alunxs, professorxs, gestorxs, vivem a sexualidade para além do livro didático, tencionando e produzindo novas configurações de ser e estar dentro da sociedade. Agenciando novos significados, desterritorializando as identidades estabelecidas pela sociedade, ou, instituições formais de ensino que visa formar corpos máquinas, manipulando suas ações e pensamentos.

Ressalto nestas asserções o papel dx professxr (não apenas elx) para conduzir aulas sobre sexualidade para além dos moldes. Pensar a sexualidade dentro/fora das aulas de biologia é imprescindível, pois estes profissionais terão o encargo de trabalhar sobre o corpo humano, no entanto, falar sobre o corpo, que não está isento dos atravessamentos referentes à sexualidade, não deve estar apenas inserido nas aulas de biologia.

Portanto, o debate acerca do corpo insere-se através da multiplicidade existencial dos saberes, não apenas na fragmentação que percorre nos discursos que o subjetivam. O corpo é a manifestação da existência humana na Terra. O corpo é produção de energia, explosão, dínamos.

Na obra Mil Platôs (2012), Deleuze e Guattari contam “como criar para si um corpo sem

Rev. Diversidade e Educação, v. 5, n. 1, p. 42-50, jan./jun. 2017. 
órgãos (CsO)", um conjunto de práticas que corroboram num $\mathrm{CsO}$ que salta os limites, em que ocorrem as mudanças, os desencontros. Este corpo não tem formas estabelecidas, nem dimensões submissas às ordens impostas socialmente. O corpo, no seu sentido múltiplo, perde sua essência orgânica e passa a ser pura conexão, como afirma Deleuze e Guattari (2012, p. 23): “O corpo é o corpo. Ele é sozinho. E não tem necessidade de órgãos. O corpo nunca é um organismo. Os organismos são os inimigos do corpo".

Quando o corpo supera as definições de organismo, ele se desarticula e entra numa desorganização caótica, o que antes era linear, se torna uma rede de conexões nas quais não se tem começo nem fim, suas zonas são extremamente abertas e flexíveis. Para Deleuze e Guattari, o CsO:

É o campo de imanência do desejo, o plano de consistência própria do desejo (ali onde o desejo se define como processo de produção, sem referência a qualquer instância exterior, falta que viria torná-lo oco, prazer que viria preenchê-lo) (DELEUZE; GUATTARI, 2012, p. 18).

$\mathrm{O} \mathrm{CsO}$ borra os binarismos impostos pela sociedade: homem/mulher, heterossexual/homossexual, branco/negro, inventando novas formas de ser. Portanto, "não se trata mais de ser homem ou mulher, mas de inventar sexos" (DELEUZE, 2008, p. 215). Destruir o corpo orgânico, e embaralhar os órgãos e os gêneros identitários que os compõem. Onde corpos sem órgãos e com n'sexos podem des/trans/configurarem-se num atravessamento indisciplinar resistente.

Diante desta premissa surgem latentes inquietações sobre até que ponto o cinema pode provocar blocos de sanções nxs professorxs e alunxs para aderirem em suas aulas questões voltadas ao pensamento da sexualidade e no embaralhamento dos corpos.

\section{Um corpo mais que bio-lógico}

Moléculas, Genes, Tecidos, Órgãos, Sistemas, Organismos... um corpo... Um corpo dividido, também ou talvez, em cabeça, tronco e membros... Fim... Estou habilitado para ensinar sobre o corpo humano. Basta saber bem o conteúdo, e claro, começar do mais geral para o mais específico de maneira linear. $\mathrm{E}$ as forças que atravessam este corpo da biologia? A sexualidade também não faz parte deste corpo? O que fazer quando a sexualidade sucumbe os corpos orgânicos? Seria a Biologia arborecente capaz de responder a tais indagações?

Os saberes nas Ciências Biológicas foram seguindo um pensamento arborecente. Através de um eixo central e suas respectivas dicotomias. Uma árvore recheada de frutos chamados classificações e definições.

Rev. Diversidade e Educação, v. 5, n. 1, p. 42-50, jan./jun. 2017. 
Este modelo insere-se continuamente nos cursos de formação de professorxs em Ciências Biológicas, formando aqueles que pensam a partir da recognição ou representação, pois “o pensamento deve estar de acordo com as coisas, com a realidade; o pensamento não pode, jamais, virtualizar, criar... Em nome da ordem, a opinião quer proteger-nos do caos” (GALLO, 2003, p. 60).

Por meio deste pensamento dogmático, muitas escolas e cursos de formação de professorxs em Ciências Biológicas se pautam. Um pensamento que se baseia em procedimentos, métodos, certificações científicas que se tornam verdades absolutas, pois

Sabemos que o projeto moderno constituiu-se em torno da construção de um método "universal" para a produção do conhecimento. Em termos filosóficos, essa busca se inicia com Descartes e com a defesa da universalização do método matemático e termina (se é que terminou)... Nesse contexto, assistimos à emergência e à consolidação da lógica disciplinar, implicando num determinado modelo de produção dos saberes e numa certa lógica da pesquisa. Parece-me que um dos pontos centrais de tal lógica disciplinar é a busca, a um só tempo, de uma objetividade e de uma universalidade do conhecimento, para que o mesmo possa ser reconhecido como válido e verdadeiro. A produção do conhecimento na modernidade foi marcada por esses princípios... (GALLO, 2006, p. 556)

No entanto, Deleuze e Guattari (2012) trazem uma nova possibilidade de pensamento, sendo este o que desterritorializa os corpos, um pensar sem imagens, um pensar do fora, que violenta e resiste, um rizoma.

Ainda refletindo sobre as indagações proferidas, no primeiro parágrafo, inerentes à sexualidade e a possibilidade, que nos traz Deleuze e Guattari, de quebrar o dogmatismo, pergunto: seria interessante pensar numa (de)formação inicial de professorxs que habilitasse os seus alunxs a pensarem para além do corpo biológico? Que afetamentos seriam desencadeados, não apenas na sua formação, mas, sobretudo, na sua futura inserção em sala de aula?

Questões como a sexualidade e interfaces no/do corpo biológico e social são negligenciadas. Contudo, penso que através de micropolíticas do cinema, podem-se pensar vias inventivas e libertárias/emancipatórias para se pensar a sexualidade e suas nuances dentro de um curso de Ciências Biológicas. Como bem nos sugere Deleuze e Guattari (2012, p. 66)

\footnotetext{
Essa linha molecular mais maleável, não menos inquietante, muito mais inquietante, não é simplesmente interior ou pessoal: ela também põe todas as coisas em jogo, mas em uma outra escala e sob outras formas, com segmentações de outra natureza, rizomáticas ao invés de arborescentes. Uma micropolítica.
}

Pensar numa (de)formação inicial em Ciências Biológicas que deforme o sentido universal de ser professxr, aquelx que é tido como detentxr do saber, e posteriormente, aquelx que irá guiar seus alunxs pelo caminho correto, como um bom pastor que apascenta suas ovelhas. Uma Rev. Diversidade e Educação, v. 5, n. 1, p. 42-50, jan./jun. 2017. 
deformação que invente novas maneiras de ser, estar e agir como professxr. Um professxr que deforme o pensamento tradicional e segmentado, descodificando-o, e em busca de linhas de fuga, para a inventividade de suas aulas.

Apresento agora alguns recortes de produções textuais em torno das obras cinematográficas. Vale ressaltar que não foi indicado o que eles deveriam produzir, ou seja, não foi direcionado nenhum sentido que possivelmente impusesse algo que se queria a partir dos filmes. Logo após foi aberto à discussão, a qual também gerou algumas impressões que serão relatadas a seguir:

Homem, mulher, macho, fêmea, XY ou XX... Durante toda a minha graduação fui levado a pensar por esses duplos. A ciência opera se não por essas classificações, ramificações. Querendo ou não reproduziremos essas concepções em nossas salas de aula. Contudo, os filmes Elvis e Madona e Uma nova amiga me fizerem refletir sobre muitas dessas verdades já postas pela ciência e a sociedade. Será que estas classificações podem dar conta de toda a multiplicidade da vida? Até quando seremos ramificados, quantificados? Não que isso não seja algo necessário, mas, após o filme e as discussões começo a pensar: por que não pensar o homem e a mulher, aliás, o ser humano a partir de outras maneiras? Qual o meu papel na sala frente à essas novas discussões sobre sexualidade que vão além do sistema reprodutor? Confesso que o filme Elvis e Madona provocou um embaralhamento na minha cabeça, fiquei confuso (professxr $\mathrm{i}^{5}$ ).

Elvis é uma mulher lésbica, mas porta-se como homem, Madona é biologicamente homem, mas verte-se como mulher, ora... No final das contas é um homem e uma mulher em corpos diferentes, mas espera, a Elvis que é mulher, mas faz papel de homem está grávida? Como assim...?! Esses foram alguns dos embaralhamentos que percorreram minha mente durante o filme. A todo tempo estava tentando categorizar, encaixar Elvis e Madona em um corpo, ora masculino, ora feminino, ora gay, ora lésbica, ora sapatão, ora travesti. Talvez essa seja a grande mensagem do filme: desconectar-nos de possíveis caixas. O filme Minha Nova Amiga traz um pouco dessas discussões também. Estamos muito presos à essas categorias... Mesmo assim

\footnotetext{
${ }^{5}$ Visando resguarda a integridade física e moral dxs participantes, optamos por utilizar pseudônimos, professxr I, II e alunx.
}

Rev. Diversidade e Educação, v. 5, n. 1, p. 42-50, jan./jun. 2017. 
é complicado discutir esse tipo de temática com alunos do ensino médio. Se nos estamos tão confusos, imagina eles... (professxr ii)

Esses filmes foram de grande importância para minha aprendizagem, não apenas no quesito escolar, mas para a vida! Ninguém sabia o que iria acontecer. Elvis e Madona é mais engraçado, é mais diferente, dá uns estranhamentos na gente. O filme minha nova amiga já é mais bonito, para refletir, para chorar em casa. Os dois são muito importantes, tratam do corpo de uma maneira diferente do que estudamos, homem pode ser mulher, mulher pode ser homem, tudo pode, tudo acontece. Hoje (não apenas por conta do filme, mas por aquilo que ele me fez pensar) me vejo e me percebo de forma diferente, pois somos mutáveis e isso nos compõem, é o que somos (alunx).

\section{Um fim que suscita inícios}

Através da análise experimentativa dos filmes é que se propõe a possiblidade de apresentálos na escola cuja função seria disparar o pensamento para falar sobre a sexualidade e questões voltadas à ela, principalmente na fissura dos gêneros, que tanto se constroem nas relações sociais, bem como proporcionar blocos de sensações configurados a partir do contato de alunxs com o cinema.

Destarte salientar que tais blocos não apenas foram explorados e experimentados, mas, que ainda, reverberarão muitos outros não-sentidos, os quais não teríamos labor para rastreá-los. Nãosentidos que potencializaram aqueles espaços (de)formativos: o corpo.

Após assistir aos filmes, ler os teóricos e artistas aqui expostos, acionaram-se algumas memórias, dentre estas, sinto-me à vontade para escrever um pequeno conto. O qual não terá sinopse, apenas, será mais uma possibilidade, além dos filmes, de ser pensado como janelas, máquinas fabuladoras de outros modos de vida. Vez ou outra pode ser armadilha, mas caso alguma das palavras, imagens ou filmes aqui expostos a qualquer momento lhe seduza. Ative o pensamento para outras vidas possíveis:

\section{Parabéns para você(s)}

Meu olhar estava fincado naquelas parafinas em chamas, decorando aquele monte de 
massa adocicada sobre a mesa. Não conseguia mais ouvir as palmas, a música, o canto que eclodia, não para mim. As luzes das chamas, sim, estas me seduziam. Lembro-me apenas da frase expurgada das cordas vocais ali presentes que diziam: “com quem será”. Certamente tal canto não me desligou do calor luminoso daquelas chamas. Teria eu a possibilidade de realizar ao menos um desejo (novamente) e ser correspondido? As chamas dançavam num sincronismo descontínuo, delirante, a magia negra que escapava me possuiu, seria esse o ritual do(s) desejo(s)? Seria agora a hora de gritar em silêncio o desejo dúbido do meu corpo? Gritei em silêncio, chorei sem lágrimas, tudo isso numa fenda temporal. A escuridão da magia negra me tragou mais um ano. As chamas apagram-se, as lâmpadas estilhaçaram-(s/e), e outra vez, me ensurdeceram ao gritarem: Vicente... Vicente... Vicente...

\section{Referências:}

BERGAlA, A. A hipótese-cinema. Tradução Mônica Costa Netto, Silvia Pimenta. Rio de Janeiro, Booklink; CINEAD-LISE-FEIUFRJ, 2008.

DELEUZE, Gilles. Ilha Deserta. Editora Iluminuras Ltda, 2008.

A imagem-tempo. São Paulo: Brasiliense, 2007. (Cinema 2).

DELEUZE, G.; GUATTARI, F. Como criar para si um corpo sem órgãos. In: . Mil Platôs. Vol.

3. Tradução de Aurélio Guerra Neto et alli. São Paulo: Ed. 34, 2012.

Mil platôs-vol. 5. Editora 34, 2012.

Oque é a filosofia? Tradução: Alberto Alonso

MUÑOZ. Editora 34, 2013.

GALLO, S. Deleuze e Educação. Belo Horizonte: Autêntica, 2003.

. Modernidade/pós-modernidade: tensões e repercussões na produção de conhecimento em educação. Educação e Pesquisa, v.32, n.3, p. 551-565, 2006.

SANTOS, H.; BRITO, M. Margens deslocadas em aulas de biologia: do sistema reprodutor a sexualidade... Linha Mestra, v. 8, n. 24, 2014.

Recebido em: 10/06/2017

Aceito em: 12/10/2017

Rev. Diversidade e Educação, v. 5, n. 1, p. 42-50, jan./jun. 2017. 